\title{
EFFECT OF GOALBALL SPORT ON PHYSICAL PERFORMANCE OF VISUALLY IMPAIRED STUDENTS
}

\author{
Tulin ATAN ${ }^{1}$, Merve AYCA ${ }^{2}$ \\ ${ }^{1}$ University of Ondokuz Mayıs, Faculty of Yaşar Dogu Sports Sciences, Samsun-Turkey \\ takman@omu.edu.tr \\ ${ }^{2}$ Tokat Provincial Directorate of Youth Services and Sports, Tokat, Turkey \\ aycamerveayca@hotmail.com
}

\section{ABSTRACT}

The aim of this study was to examine the effect of three month goalball sport on physical performance of visually impaired students. 38 visually impaired male students attending to the primary school were participated the study. 19 of them were separated as an exercise group (age; $13.15 \pm 1.59$ years) and the rest 19 subject were separated as a control group (age; $13.30 \pm 1.43 y e a r s)$ randomly. Exercise group do goalball sport three days a week for three months. Before and after the exercise program some physical performance tests were applied to all 38 students. To measure the physical performance; audial reaction time, $10 \mathrm{~m}$ running time, standing long jump, grip strength, vertical jump, and flexibility values were measured. The physical performance measured before the start of the three month exercise did not show meaningful difference between two groups ( $p>0.05)$. But when the values after three month were compared, it was found that audial reaction time, standing long jump, grip strength, $10 \mathrm{~m}$ speed running time, vertical jump and flexibility levels of the group doing goalball exercise was statistically better than that of the control group $(p<0.01$ and $p<0.05)$. As a conclusion it has been seen that the goalball sport enhance the physical performance of visually-impaired students.

\section{Indexing terms/Keywords}

Goalball; visually impaired; physical performance.

\section{Academic Discipline And Sub-Disciplines}

Sports and Exercise

\section{SUBJECT CLASSIFICATION}

Sports and Exercise

\section{TYPE (METHOD/APPROACH)}

\section{Experimental}

\section{Council for Innovative Research}

\section{Peer Review Research Publishing System}

\section{Journal: Journal of Social Sciences Research}

Vol. 7 , No. 1

jssreditor.cir@gmail.com 


\section{INTRODUCTION}

Visually impaired individuals constitute some part of handicapped people who are experiencing non-ignorable challenges in the community. Learning is the most important element that allows people to adapt their environment and sustain their lives. Eyes and ears are the two most important sense organs that play a crucial role for learning (Caliskan et al., 2007). Visual loss does not directly leads to loss of motor or physical function but developmental function because of insufficient physical activity, including inactivity, manipulating the environment and having limited experience with the environment. Delay in motor development is not seen in individuals who subsequently lost sight, but those who previously lost their sights may have delays in motor development (Ozer, 2001).

Doing sport is important both for physical and psychological development in everyday life and the elimination of nerve, muscle and joint coordination problems which result from insufficient physical activity (Keskin, 2008). Sport contributes to the elimination of inevitable fear of getting harm from the environment and living a more independent life (Caliskan et al., 2007).

Goalball is one of the most common sports among visually impaired people. It was first invented after the World War II in effort to help in the rehabilitation of blinded German war veterans. Because the degree of visual impairment may vary among players, they wear eye patches to ensure complete coverage of the eye (Caliskan et al., 2007). The number of disabled people throughout the world is substantial so the barriers preventing the handicapped people's participation in sport activities needs to be removed (Keskin, 2008). Although visually impaired students have lower levels of physical fitness, there are some visually impaired students whose physical fitness levels are higher than those of their sighted peers (Caliskan et al., 2007).

The aim of this study is to investigate the development of visually impaired children by measuring their physical performances before and after goalball sport.

\section{MATERIALS AND METHODS}

19 male students, at the age of average $13,15 \pm 1,59$ years and 19 male students at the age of average $13,30 \pm 1,43$ years studying at Tokat Mehmet Akif Ersoy Primary School for the Visually Impaired participated in this study as the exercise group and the control group respectively. This research was carried out under the verdict of Ondokuz Mayıs University ethical committee.

In this study, performances of 38 students were tested. Then, randomly 19 students were assigned as control group. The remaining 19 students were subjected to goalball sports and measurements were repeated after three months (pre-test and post-test). Visually impaired students were subjected to the following tests;

Standing Long Jump Test: Subjects got ready in a predetermined starting line at the gym, and were asked to jump forward with all their strengths. The distance between the starting line and the latest contact area was measured in $\mathrm{cm}$ and recorded. In order to conquer their fear, jumping was repeated before the study.

Reaction Time (RT) Test: The measurements of auditory reaction time of the subjects participating in the study were made using Newtest 1000 instrument. The instruments provides auditory (sound) stimulus. Measurements were made in a noise-free environment. Information form was created for each subject for the recording of the measurement results. Newtest 1000 device was placed at a distance of $10 \mathrm{~cm}$ from the table and the subjects were asked to put their dominant hands on to the table and to press the button as soon as possible after hearing the stimuli sound. Each subject had 10 tries, the first five tries were considered as trial practice and the mean of five last attempts was assigned as reaction time.

Hand grip strength test: The measurements of isometric strength of the hand and forehand muscles were made with digital hand grip dynamometer. The subjects were asked to stand up with the hands down and to squeeze the digital hand dynamometer with maximum isometric effort. The subject squeezed the digital hand dynamometer with maximum effort and the value on the screen was recorded in $\mathrm{kg}$. The best result of two trials was recorded.

10 m Running Time Test: Speeds of the subjects were measured using Newtest photocell. Two photocells, one in the starting point and one in the endpoint, were placed (10 meter). The subject passed through the starting photocell and sprinted to the finish line with the help of a sighted person. The best result of two measurements was recorded.

Anaerobic Power: Vertical jump test was used for the measurement of anaerobic power of the visually impaired students participating in the study. The subject outstretched their arms on their heads in front of the metric panel and the point where the hand fingertips touched was marked. The subjects turned to the right side and tried to touch the highest point on the wall and left a mark with chalk dust. The distance between the points was recorded as the vertical jump height. The best result of two trials was considered as the best score. Anaerobic power was calculated using the following formula proposed by Fox et al. (1988).

Anaerobic power $(\mathrm{kgm} / \mathrm{s})=\sqrt{ } 4.9 \times$ (body weight) $\times \sqrt{ } D$

$D=$ vertical jump distance $(m)$

Flexibility Measurements: Trunk Flexion Meter was used for sit and reach test. For this test, visually impaired students were asked to sit down on the floor barefoot and to rest their soles of feet to the test tripod and to push the digital 
display on the tripod forward without bending their legs. The subject was kept for 1-2 seconds on the maximum point and indicator values were recorded. This procedure was repeated three times, the best value was evaluated.

These measurements were done twice (before and after three-month goalball training) and the differences between exercise group and control group were examined.

Exercise Practised: Exercise group was made to do goalball sport for one hour three days a week within three months.

The students were made to do short running and 10-minute stretching exercises at the beginning of every training, and afterwards, they were made to do several exercises in order for them to perceive the goalball through sound.

- Two students, made to sit opposite in a short distance, were asked to roll the ball towards each other, and the distance was increased in every training.

- Later, the exercises of lying to the right and left according to the voice. For instance, first of all, the students were made to do the exercises of lying to both sides without the ball.

- After these exercises ended successfully, exercises with the ball started. In the following exercises, the students were told the direction to which the ball was thrown; however, upon the increase of their reaction, or in the next trainings, they were asked to catch the ball focusing on the sound without telling the direction of the thrown ball. The students were asked to run after the ball in a slow pace after the ball was rolled on the ground. Then they were asked to turn the ball around their waist and their legs, and to increase the speed in each training.

- In order to strengthen the arms, they were requested to wait holding the ball top, in front, on the right and on the left without bending elbows in the sitting position. In the following trainings, they were asked to spin the ball with their fingers.

- The students were asked to do some stepping from the goal to the highball line and count them. Then they continued doing walking and jogging, and they were asked to run in the next training. By the help of this exercise, the students memorized the lines.

- Through such kinds of warming, exercises and games, exercise period was completed in 12 weeks.

\section{Statistical Analysis:}

The data obtained from the research were analyzed in SPSS version 19.0 package program. Kolmogorov Smirnov test was used if the continuous variables exhibit a normal distribution or not. For non-normal variables Mann Whitney-U test was used and values were presented as Mean, Standard Deviation (SD), Median, Minimum (min) and Maximum (max). For normal variables, Independent $t$ test was used and values were presented as Mean and SD.

\section{RESULTS}

The datas obtained from this study were shown in tables.

Table 1: Physical Feature of Subjects

\begin{tabular}{|c|l|c|c|c|}
\hline Parameters & Group & $\mathbf{n}$ & Mean \pm SD & p \\
\hline \multirow{2}{*}{ Age (year) } & Exercise & 19 & $13.15 \pm 1.59$ & \multirow{2}{*}{0.378} \\
\cline { 2 - 4 } & Control & 19 & $13.30 \pm 1.43$ & \\
\hline \multirow{2}{*}{ Height $(\mathrm{cm})$} & Exercise & 19 & $149.56 \pm 4.32$ & \multirow{2}{*}{0.231} \\
\cline { 2 - 4 } & Control & 19 & $148.08 \pm 5.87$ & \\
\hline \multirow{2}{*}{ Body Mass $(\mathrm{kg})$} & Exercise & 19 & $41.70 \pm 9.48$ & \multirow{2}{*}{0.218} \\
\cline { 2 - 4 } & Control & 19 & $40.05 \pm 8.33$ & \\
\hline
\end{tabular}

Table 2: RT and $10 \mathrm{~m}$ Sprint Time Values of Subjects

\begin{tabular}{|c|c|c|c|c|c|}
\hline Parameters & Group & $\mathbf{n}$ & Mean $\pm S D$ & Median (min;max) & $\mathbf{p}$ \\
\hline \multirow{2}{*}{ Pre-test RT (msec) } & Exercise & 19 & $280.27 \pm 83.21$ & 251.25 (149.00; 429.50) & \multirow{2}{*}{0.161} \\
\hline & Control & 19 & $263.69 \pm 77.48$ & $236.50(179.50 ; 496.00)$ & \\
\hline \multirow{2}{*}{ Post-test RT (msec) } & Exercise & 19 & $200.33 \pm 29.69$ & $185.00(168.00 ; 269.00)$ & \multirow{2}{*}{$0.004^{* *}$} \\
\hline & Control & 19 & $259.18 \pm 58.48$ & $230.00(178.00 ; 450.00)$ & \\
\hline \multirow{2}{*}{ Pre-test running time (sec) } & Exercise & 19 & $3.22 \pm 0.95$ & $2.97(2.27 ; 5.85)$ & \multirow{2}{*}{0.675} \\
\hline & Control & 19 & $3.47 \pm 1.11$ & $3.16(2.19 ; 5.13)$ & \\
\hline \multirow{2}{*}{ Post-test running time (sec) } & Exercise & 19 & $2.95 \pm 0.86$ & $2.60(2.11 ; 5.48)$ & \multirow{2}{*}{$0.044^{*}$} \\
\hline & Control & 19 & $3.67 \pm 1.16$ & $3.21(2.22 ; 5.28)$ & \\
\hline
\end{tabular}

${ }^{* *} p<0.01{ }^{*} p<0.05$ 
No statistically significant difference was observed in the initial reaction measurements of exercise (goalball group) and control groups $(p>0.05)$. When compared with the control group, we observed decrease in reaction times in exercise group after a three-month training $(p<0.01)$.

While there was no statistically significant difference between two groups in terms of initial $10 \mathrm{~m}$ sprint time ( $p>0.05)$, we observed statistically significantly shorter sprint times in exercise group after a three-month training $(p<0.05)$. Comparison of two measurements revealed statistically significant difference between control and exercise group $(p<0.01)$.

Table 3: Standing Long Jump Values of Subjects

\begin{tabular}{|c|c|c|c|c|}
\hline Standing Long Jump Distance (cm) & Group & $\mathbf{n}$ & Mean $\pm S D$ & $\mathbf{p}$ \\
\hline \multirow{2}{*}{ Pre-test Double Foot } & Exercise & 19 & $110.25 \pm 21.30$ & \multirow{2}{*}{0.230} \\
\hline & Control & 19 & $112.22 \pm 31.53$ & \\
\hline \multirow{2}{*}{ Post-test Double Foot } & Exercise & 19 & $119.50 \pm 18.00$ & \multirow{2}{*}{$0.035^{*}$} \\
\hline & Control & 19 & $112.77 \pm 35.81$ & \\
\hline \multirow{2}{*}{ Pre-test Right Foot } & Exercise & 19 & $93.70 \pm 23.36$ & \multirow{2}{*}{0.258} \\
\hline & Control & 19 & $94.33 \pm 33.66$ & \\
\hline \multirow{2}{*}{ Post-test Right Foot } & Exercise & 19 & $96.65 \pm 19.79$ & \multirow{2}{*}{$0.048^{*}$} \\
\hline & Control & 19 & $93.50 \pm 31.64$ & \\
\hline \multirow{2}{*}{ Pre-test Left Foot } & Exercise & 19 & $92.75 \pm 17.22$ & \multirow{2}{*}{0.267} \\
\hline & Control & 19 & $92.11 \pm 34.13$ & \\
\hline \multirow{2}{*}{ Post-test Left Foot } & Exercise & 19 & $94.80 \pm 16.35$ & \multirow{2}{*}{$0.034^{*}$} \\
\hline & Control & 19 & $92.38 \pm 34.30$ & \\
\hline
\end{tabular}

No statistically significant difference was observed between two groups in terms of pre-test long jumping values ( $p>0.05$ ). After a three-month training, long jumping values in the exercise group were found to be significantly higher than those in control group $(p<0.05)$.

Table 4: Hand Grip Strength Values of Subjects

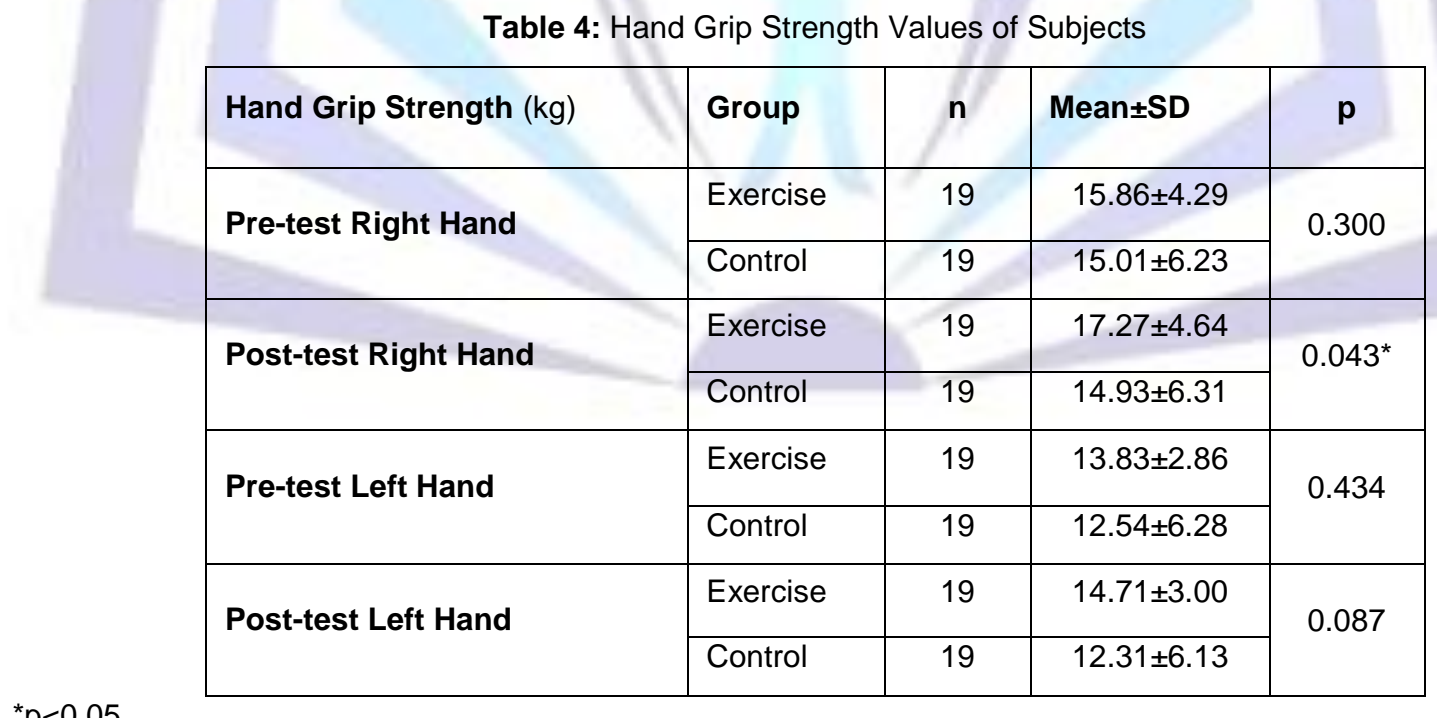

${ }^{*} \mathrm{p}<0.05$

No statistically significant difference was observed between two groups in terms of initial right hand grip strength values ( $p$ $<0.05)$. After three-month training, right hand grip strength values in exercise group was found statistically higher than those in the control group $(p<0.05)$. Comparison of two measurements revealed statistically significant difference in favor of post-test $(p>0.05)$.

Again, there was no statistically significant difference between two groups in terms of initial left hand grip strength values $(p<0.05)$. After three-month training, no statistically significant difference was observed between two groups $(p>0.05)$. 
Table 5: Anaerobic Power and Flexibility Values of Subjects

\begin{tabular}{|l|l|c|c|c|}
\hline Parameters & Group & $\mathbf{n}$ & Mean \pm SD & p \\
\hline \multirow{2}{*}{$\begin{array}{l}\text { Pre-test Anaerobic Power } \\
(\mathrm{kgm} / \mathrm{sn})\end{array}$} & Exercise & 19 & $48.34 \pm 7.89$ & \multirow{2}{*}{0.456} \\
\cline { 2 - 4 } & Control & 19 & $49.32 \pm 9.23$ & \\
\hline $\begin{array}{l}\text { Post-test Anaerobic Power } \\
(\mathrm{kgm} / \mathrm{sn})\end{array}$ & Exercise & 19 & $51.45 \pm 6.83$ & \multirow{2}{*}{$0.034^{*}$} \\
\cline { 2 - 4 } & Control & 19 & $48.88 \pm 8.64$ & \\
\hline \multirow{2}{*}{ Pre-test Flexibility $(\mathrm{cm})$} & Exercise & 19 & $13.67 \pm 5.75$ & \multirow{2}{*}{0.212} \\
\cline { 2 - 4 } & Control & 19 & $13.53 \pm 8.50$ & \\
\hline \multirow{2}{*}{ Post-test Flexibility $(\mathrm{cm})$} & Exercise & 19 & $17.77 \pm 5.99$ & \multirow{2}{*}{$0.011^{*}$} \\
\cline { 2 - 4 } & Control & 19 & $14.01 \pm 7.66$ & \\
\hline
\end{tabular}

${ }^{*} \mathrm{p}<0.05$

Comparison of anaerobic power measurement revealed no statistically significant difference between two groups in terms of pre-test values $(p<0.05)$. But after a three-month-training these values differed significantly $(p<0.01)$. Comparison of two measurements showed statistically significant difference between two groups in favor of exercise group $(p<0.05)$. There were no statistically significant differences between groups in terms of initial flexibility measurements $(p>0.05)$. However, post-measurements revealed significant increase in the flexibility of students in the exercise group.

\section{DISCUSSION}

This study aimed to examine the effect of goalball training on physical performance of visually impaired students. In the RT test, while comparison of control and exercise group measurements revealed no significant difference before threemonth training; revealed significant differences after training. Exercise group showed improvement in RT after 12-week training. The results of the previous studies also support the results of our study. In their study investigating the effect of goalball and movement education on physical fitness of visually impaired children, Caliskan et al. (2007) found significant differences in auditory reaction times after a three-month-exercise. Yildirim et al. (2011) investigated the effect of 12-week tennis training on visual and auditory reaction times in girls aged 8-10 years and found significant differences in children's auditory reaction times after a three-month tennis training. Again, Büyükipekci and Taskin (2011) investigated the changes in reaction time, agility and anaerobic performance in female volleyball players by measuring the auditory reaction levels in the beginning and the end of the season and found no significant difference. These different results can be attributed to two reasons; the subjects in our study were visually impaired students and they had not had sportive activity before.

In $10 \mathrm{~m}$ sprint test, when compared with the values obtained in three months ago, significant decreases were observed in the sprint times of the students in exercise group. These values remained unchanged in the control group. Demir (2006) investigated the effect of 10 -week training program on some motor functions of educable mentally retarded male adolescents and identified 30 educable mentally retarded children (15 in control group and 15 in experimental group). Adolescents in experimental group received 10-week-training (one and a half hour day, three times a week) but those in control group were not subjected to any training program. At the end of the 10-week training, while there was no statistically significant difference in the sprint times in control group, sprint time values showed decreases in experimental group. Kirici (2008) also investigated the influence of eight-week movement education on motor performance of pre-school children aged 4-6. While there was no statistically significant difference between control and experimental groups with respect to the sprint time measurements taken before the exercise, a decrease was observed in the sprint times of experimental group after an eight-week exercise. In his study investigating the role and importance of game in achieving psychomotor developments of 6-year-old students, Ozdenk (2007) had 46 children done exercise in 30 sessions. He compared pretest and posttest results and found that post-exercise sprint times were shorter than pre-exercise sprint times. Sahin (2007) investigated the influence of regular exercise training on some physical and physiological parameters of children aged 12-14 years. At the end of the two-month experiment, he observed that sprint time values in control group remained unchanged but decreased in experimental group.

Pre-test long jumping values were not statistically different between two groups. After a three-month training, long jumping values in the exercise group were found to be significantly higher than those in control group. Results of many studies are consistent with the findings of our study (Bicer et al., 2004; Pekel, 2006; Kizilaksam, 2006; Sofi, 2002; Zambak, 2008). In their study investigating the effect of strength and power exercises on movement skills and abilities of mentally challenged children, Bicer et al. (2004) observed significant differences between pre-training and post-training measurements of standing long jump. Pekel (2006) determined increases in standing long jumping values of athletes. Results of these studies show parallelism with our study results. In his study comparing the physical differences in students (aged 12 14years) from primary schools in Edirne province (the students were actively engaged in sports or not), Kizilaksam (2006) determined that long jump scores of the students participating in sportive activities were higher than those of students not. Sofi (2002) investigated the physiological and physical changes in football players before pre-season and after preparation periods and found that standing long jump scores of the football players were higher than those measured pre-season period. Zambak (2008) gave experimental group an 8-week heavy exercise program. On the other hand, individuals in the 
control group continued their normal trainings. After eight-week training program, an increase was observed in the standing long jump measurements of experimental group.

In hand grip strength test, while the right hand grip strength of exercise group showed improvement, no statistically significant changes was observed in left hand grip strength values after the three-month-training. However, these values in the control group did not change significantly. Top (2007) investigated the effects of 14-week physical activity programs on visually impaired children aged 10-12 and observed increases in both right and left hand grip strength. Marangoz (2008) compared some physical and physiological properties of football players from Kahramanmaras and Siirtspor football clubs during the season and found no statistically significant differences between preseason and postseason right and left hand grip strength values. Celebi (2008) investigated structural and functional properties of elementary school students (aged 9 13) attending swimming training. He divided them into two groups as control (no training group) and experimental groups (training group) and found no statistically significant differences in right and left hand grip strength values of the students in both control and groups at the end of 12-week training. This is due to the fact that football players and swimmers are professionals but the subjects in our study were visually impaired children and they had not engaged any sportive activities before.

In vertical jump test, pre-test values of anaerobic power revealed no statistically significant difference between two groups. But after a three-month-training, comparison of two measurements showed statistically significant difference between two groups in favor of exercise group $(p<0.05)$. Ates and Atesoglu (2007) investigated the effect of plyometric training on upper and lower extremity strength parameters of male football players (aged 16-18 years) and found significant differences in the vertical jump values of exercise group but no difference in the control group. The results of this study are consistent with those obtained in our study. Baktal (2008) investigated the effect of plyometric exercise on vertical jump values of 16-22 year-old female volleyball players and observed that doing plyometric exercise for one season had no influence on vertical jump values. Aslan (2008) examined the influence of flexibility on jumping and leg strength in sedentary and physically active individuals and found that vertical jump values of sedentary subjects were lower than the vertical jump values of physically active individuals. Kuru (2009) examined the impact of game on psycho-motor development of nine-year-old children. After applying a pretest to the third grade students, he had children to play games that may contribute to their motor development for two hours per week. Post-test results after14-week exercise period showed significant differences in the vertical jump values of the children.

In this study, although there were no significant differences in flexibility scores of the control group after a three-month exercise, significant increases were observed in flexibility scores of exercise group. Yilmaz et al. (2008) investigated the impact of doing judo on visually impaired students in terms of some parameters and found significant differences in flexibility parameters in visually disabled students at the end of two months. Again, Ciftci (2006) investigated the influence of 8-week training program on flexibility parameters of first and eighth grade hearing impaired students and found significant differences in students' flexibility scores after an eight-week training. In his study investigating the effect of 8 week plates training on flexibility and balance in women aged 40-45 years, Caglar (2005) found that flexibility scores increased in the experimental group but remained unchanged in the control group. The results of these studies are consistent with those obtained in our study.

\section{CONCLUSIONS AND RECOMMENDATIONS}

In conclusion, physical performance of the visually impaired students participating in goalball training positively changed in comparison to those not participating training. Therefore, visually impaired individuals should be encouraged to participate in sportive and physical activities.

\section{ACKNOWLEDGEMENTS}

This study forms part of a thesis of Merve Ayca.

\section{REFERENCES}

1. Aslan C.S. 2008. The evaluation of the effects of flexibility on vertical jump and leg strength in sedantaries and physically active person. Master Thesis, Cumhuriyet University Institute of Health Sciences, Sivas.

2. Ates $M$, Atesoglu U. The effect of plyometric training on the strength parameters of upper and lower extremities of 16-18 years old male soccer players. Spormetre Journal of Physical Education and Sports Science. 2007; V(1): 21-28.

3. Baktal, D.G. 2008. The research about plyometric training models on vertical jump in 16-22 age female volleyball players. Master Thesis, Cukurova University Institute of Health Sciences, Adana.

4. Bicer Y, Savucu Y, Kutlu M, Kaldirimci M, Pala R. The effect of power and strength exercises on movement competence and ability of mentally disabled children. Fırat University Eastern Anatolia Region Research Journal. 2004; 3(1):173-179.

5. Büyükipekci S, Taskin H. (2011). The effect of changes in reaction time, agility and anaerobic performance during the all season in female volleyball players. Selcuk University Journal of Physical Education and Sports Science. $2011 ; 13(1): 20-25$.

6. Caglar, F. 2005. The effects of 8 week pilates exercise on balance and flexibility. Master Thesis, Mugla University Institute of Social Sciences, Mugla. 
7. Caliskan E, Karagözoglu C, Kayapinar F, Erzeybek S, Fisekcioglu B. The effects of goalball game and movement training on the anxiety traits of visually impaired children. Atatürk University Journal of Physical Education and Sports Science. 2007; 9(3): 22-35.

8. Celebi, S. 2008. We investigate body structural and functional properties in 9-13 year children who takes swimming training. Master Thesis, Erciyes University Institute of Health Sciences, Kayseri.

9. Ciftci, D. 2006. The physiological response the hear of deaf primary school $1^{\text {st }}$ grade and $8^{\text {th }}$ grade students to 8 week training programme. Master Thesis, Sakarya University Institute of Social Sciences, Sakarya.

10. Demir, R. 2006. The effect on some motor abilities of 10 weeks training programs of educationable mentally male adolescents. Master Thesis, Nigde University Institute of Social Sciences, Nigde.

11. Fox EL, Bowers RW, Foss ML. 1988. The Physiological Basis of Physical Education and Athletics. 4th edition. Saunders, Philadelphia.

12. Keskin, S. 2008. The comparison of auditory simple reaction times of employees between 18-30 age of the General Directorate of Youth and Sport who make sports with the visually-impaired individuals between 18-30 age who make sports. Master Thesis, Gazi University Institute of Health Sciences, Ankara.

13. Kirici, H.M. 2008. The effect of movement education of eight weeks on the motor performance of 4-6 years old children in preschool. Master Thesis, Mugla University Institute of Social Sciences, Mugla.

14. Kizilaksam, E. 2006. The comparison of the battery of eurofit tests' results about the group of students, ages 12 14 , athletes and sedentary (participated physical education lesson) at the schools of elementary education in Edirne. Master Thesis, Trakya University Institute of Health Sciences, Edirne.

15. Kuru, O. 2009. The influence of the games on the psychomotor development of the children at the age of nine. Master Thesis, Fırat University Institute of Social Sciences, Elazıg.

16. Marangoz, I.A. 2008. Comparison with physical and physiological characteristics of Kahramanmaras and Siirtspor Professional football teams at the competition season. Master Thesis, Sutcu Imam University Institute of Social Sciences, Kahramanmaras.

17. Ozdenk, C. 2007 The place and importance of play for psychomotor development of six-years age group nursery students. Master Thesis, Firat University Institute of Social Sciences, Elazıg.

18. Ozer DS. 2001. Engelliler İçin Beden Eğitimi ve Spor. Nobel Publication, First Issue, Ankara.

19. Pekel HA. The evaluation relationship between some anthropometric characteristics and performance related physical fitness test result in children athletes. Kastamonu Education Journal. 2006; 14(1): 299-308.

20. Sofi, N. 2002. A research about changes on some physiological and physical changes in body between before preparation period and after preparation period in before the season. Master Thesis, Kırıkkale University Institute of Health Sciences, Kırıkkale.

21. Sahin, O. 2007. The investigation of effects of regular exercise training on some physical and physiological parameters in 12-14 aged children. Master Thesis, Selcuk University Institute of Health Sciences, Konya.

22. Top, C.E. 2007. The effect of 14 weeks physical activity program on children with visual impairment 10-12 years old. Master Thesis, Akdeniz University Institute of Health Sciences, Antalya.

23. Yildirim I, Karagöz S, Ocak Y. Inspection of the effects of twelve-week tennis courses on visual and auditory reaction times of 8-10 years old girl children. Nigde University Journal of Physical Education and Sport Sciences. 2011; 5(3): 256-257.

24. Yilmaz S, Tatar $Y$, Ates $O$, Tiryaki E. Judo sporunun görme engelli öğrenciler üzerine etkisinin bazı parametreler açısından incelenmesi. Istanbul University Sports Science Journal. 2008; 11(3): 173-176.

25. Zambak, O. 2008. Effect of quick strength training on physical and physiological parameters of male basketball players. Master Thesis, Gazi University Institute of Health Sciences, Ankara. 